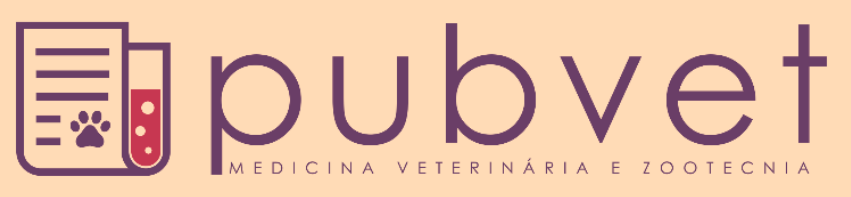

https://doi.org/10.31533/pubvet.v14n8a632.1-4

\title{
Linfoma canino: Revisão
}

\author{
Gabriela Fonseca Horta ${ }^{1 *}$ \\ ${ }^{I}$ Graduanda em medicina veterinária no Centro Universitário de Belo Horizonte. Belo Horizonte - MG Brasil. \\ *Autor para correspondência, e-mail: gabrielahorta@outlook.com
}

Resumo. O linfoma canino é uma enfermidade configurada pelo crescimento incontrolado de células do sistema linfático, como por exemplo os linfócitos. Acomete principalmente cães machos de raças grandes, de meia idade a idosos. O intuito desta revisão de literatura é agregar informações relevantes a respeito desta neoplasia que afeta os cães, visto que é o tumor do tecido hematopoiético de maior ocorrência nos mesmos.

Palavras chave: cães, linfoma, tecido linfoide

\section{Canine lymphoma: Review}

Abstract. Canine lymphoma is a disease characterized by uncontrolled growing of cells in the lymphatic system, such as lymphocytes. It mainly affects male dogs of large breeds, from middle age to the elderly. The aim of this literature review is to add important information on neoplasm that affects dogs, since it is the tumor of the hematopoietic tissue with the highest occurrence in them.

Keywords: dogs, lymphoid tissue, lymphoma

\section{Linfoma canino: Revisión}

Resumen. El linfoma canino es una enfermedad configurada por el crecimiento incontrolado de células en el sistema linfático, como los linfocitos. Afecta principalmente a perros machos de razas grandes, desde la mediana edad hasta los ancianos. El propósito de esta revisión es agregar información relevante sobre esta neoplasia que afecta a los perros, ya que es el tumor del tejido hematopoyético con la mayor incidencia en ellos.

Palabras clave: linfoma, perros, tejido linfoide

\section{Introdução}

O linfoma é uma neoplasia maligna que acomete órgãos linfoides (OL) como baço, fígado e linfonodos (Cardoso et al., 2004). É o tumor do tecido hematopoiético que mais ocorre em cães (Moura et al., 1999). Os OL compõem o sistema imune do indivíduo. Sua principal função é o processamento e apresentação de antígenos e a expansão clonal. O linfoma, também chamado de linfossarcoma, é caracterizado pela multiplicação desordenada de células oriundas do tecido linfoide (Fighera, 2002). A frequente exposição às substâncias químicas é apontada como uma das causas predeterminantes do surgimento de linfoma em cães. A ocorrência dessa neoplasia é maior em machos, de meia idade a idosos, e em raças de grande porte como Pastor Alemão, Boxer, Dobbermann e Rottweiler (Silva \& Sequeira, 2016). Os sinais clínicos podem ser, na maioria das vezes, inespecíficos, e podem variar de acordo com o órgão envolvido e com a imunidade do animal. Linfadenomegalia indolor, perda de peso progressiva, caquexia, anorexia, edema local ou generalizado, apatia e êmese são os sinais mais frequentes (Moura et al., 1999). O diagnóstico é feito através de sinais clínicos, radiografia torácica e abdominal, ultrassonografia abdominal, exames laboratoriais como hemograma, perfil bioquímico com dosagem de cálcio, perfil sérico renal e hepático, urinálise, punção 
aspirativa por agulha fina, biópsia da região acometida, classificação histológica, imunofenotipagem e técnicas moleculares. O linfoma é um dos tumores que melhor responde à quimioterapia, sendo este o método terapêutico de eleição, capaz de aumentar a duração e a qualidade de vida do paciente significativamente (Silva \& Sequeira, 2016).

Este trabalho objetiva reunir informações importantes sobre o linfoma em cães, obtidas por meio de revisão bibliográfica utilizando artigos científicos encontrados na plataforma de dados Google Acadêmico. O que é o linfoma, quais são os fatores predisponentes, como é classificado, sinais clínicos apresentados, formas de diagnóstico e tratamento são alguns dos assuntos abordados.

\section{Desenvolvimento}

\section{Fatores predisponentes}

Eventos genéticos, deficiência imunológica, exposição à radiação ionizante, carcinógenos químicos e aberrações cromossômicas são alguns dos fatores predisponentes do linfoma canino (Ribeiro et al., 2017). A exposição crônica a substâncias químicas pode predeterminar o desenvolvimento de linfoma em cães (Moura et al., 1999).

\section{Classificação}

Os linfomas podem ser classificados de acordo com sua localização em: multicêntrico, alimentar, tímico, cutâneo e solitário/extra nodal. O de maior ocorrência é o multicêntrico, logo após vem o alimentar (Moura et al., 1999). A forma multicêntrica acomete linfonodos superficiais e profundos, baço, fígado, tonsilas e medula óssea. A forma alimentar acomete o trato gastrintestinal e/ou linfonodos mesentéricos. A forma tímica acomete o timo e linfonodos regionais. A forma cutânea acomete a pele e a solitária envolve apenas um órgão (Fighera et al., 2006; Souza et al., 2006).

\section{Sinais clínicos}

\section{Linfoma multicêntrico}

O linfoma multicêntrico pode causar linfoadenomegalia, hepatomegalia e esplenomegalia pela infiltração neoplásica, vômito, diarreia, dispneia, poliúria, polidipsia, ascite e hipertermia (Cardoso et al., 2004).

\section{Linfoma alimentar}

Os sinais clínicos gerados pelo linfoma alimentar são: vômito, diarreia e estearorréia decorrentes da síndrome da má absorção. O espessamento segmentar do intestino pode gerar obstrução parcial. Se a neoplasia infiltrar-se na mucosa do intestino delgado, com ulceração, pode ocorrer melena (Cardoso et al., 2004).

\section{Linfoma tímico}

Quando há linfoma tímico pode-se observar poliúria e polidipsia, que são secundárias à hipercalcemia, que pode gerar também hipercalciúria, lesão renal e urolitíase. Além disso, intolerância ao exercício, taquipnéia, dispnéia, ortopnéia, tosse, cianose, síncope, regurgitação, anorexia, caquexia e letargia também são sinais clínicos descritos em decorrência da compressão provocada pela neoplasia tímica (Cardoso et al., 2004).

\section{Linfoma cutâneo}

Lesões na pele com distribuição multifocal ou generalizada, em forma de placas ou nódulos ulcerados e eritrodermia esfoliativa são alguns dos sinais clínicos provocados pelo linfoma cutâneo; outros sinais são: alopecia, seborreia, prurido, ulcerações e despigmentação mucocutânea, principalmente em mucosa oral e conjuntival (Cardoso et al., 2004).

\section{Linfoma solitário ou extra nodal}

Como o linfoma solitário/extra nodal pode acometer qualquer tecido corporal, os sinais clínicos variam, estando sempre relacionados ao órgão acometido (Cardoso et al., 2004). 


\section{Diagnóstico}

O diagnóstico de linfoma é obtido através da soma dos sinais clínicos, radiografia torácica e abdominal, ultrassonografia e exames laboratoriais como hemograma, perfil bioquímico com dosagem de cálcio (Moura et al., 1999), além de perfil sérico renal e hepático, e urinálise, que indicam a extensão e o grau de comprometimento orgânico (Ribeiro et al., 2017). A citologia e a histopatologia são os exames confirmatórios. A citologia aspirativa por agulha fina e a imunofenotipagem classificam a neoplasia quanto ao tipo celular. A biópsia de regiões acometidas e a imunohistoquímica classificam histologicamente a neoplasia, apontando o prognóstico e a melhor conduta terapêutica a ser aplicada. A imunofenotipagem também pode ser feita para determinar a origem celular, o que contribui no prognóstico e na escolha do tratamento (Moura et al., 1999). Técnicas moleculares podem aumentar a exatidão do diagnóstico e ajudar a compreender o comportamento tumoral. Alguns recursos importantes que auxiliam no diagnóstico são a ecocardiografia, a tomografia axial computadorizada e a ressonância magnética nuclear (Ribeiro et al., 2017).

\section{Tratamento}

A principal conduta terapêutica para o tratamento do linfoma canino consiste em quimioterapia antineoplásica, sendo este o tumor que melhor responde a esse tipo de tratamento, exceto os linfomas indolentes, que não respondem. Fármacos antineoplásicos causam toxicidade, especialmente ao parênquima hepático. Portanto, é recomendado o monitoramento periódico de animais que estejam sendo tratados através de quimioterapia. Os agentes quimioterápicos mais eficazes para o tratamento do linfoma são doxorrubicina, L-asparaginase, vincristina, ciclofosfamida e prednisona ou prednisolona. A poliquimioterapia é mais efetiva em relação à quimioterapia, isso pois as linhagens de células linfomatosas contribuem para a resistência quimioterápica. A poliquimioterapia é dividida em fases: indução da remissão, intensificação se não houver remissão completa na primeira fase, manutenção para prolongar e manter a remissão, além dos protocolos de emergência ou resgate, que têm como objetivo induzir nova remissão (Ribeiro et al., 2017).

\section{Prognóstico}

O prognóstico é reservado para cães que possuem linfoma. Os diferentes tipos de linfoma apresentam comportamento distinto, o que pode influenciar diretamente no prognóstico. A imunidade, estado geral do animal, raça, sexo e idade também interferem no estabelecimento do prognóstico (Moura et al., 1999). Em cães, a taxa de cura é baixa e o tempo estimado de sobrevida após o tratamento é de 12 a 16 meses (Ribeiro et al., 2017).

\section{Considerações finais}

O linfoma é uma afecção de caráter maligno caracterizada pelo desenvolvimento de neoplasia em órgãos linfoides. Sua causa ainda é discutida, mas já foram apontadas algumas condições que parecem favorecer o aparecimento desse tipo de câncer. Os sinais clínicos apresentados dependem da região afetada pelo tumor, imunidade do animal, estágio da doença, dentre outros fatores. É importante diagnosticar e classificar o tipo de linfoma para melhor escolha da conduta terapêutica que será aplicada. Como a probabilidade de cura é baixa, o tratamento também tem como objetivo trazer qualidade de vida ao paciente oncológico.

\section{Referências bibliográficas}

Cardoso, M. J. L., Machado, L. H. A., Moutinho, F. Q., \& Padovani, C. R. (2004). Sinais clínicos do linfoma canino. Archives of Veterinary Science, 9(2), 19-24. DOI: https://doi.org/10.5380/avs.v9i2.4059

Fighera, A. R. (2002). Linfossarcoma em cães. Ciência Rural, 32(5), 895-899.

Fighera, R. A., Souza, T. M., Rodrigues, A., \& Barros, C. S. L. (2006). Aspectos clinicopatológicos de 43 casos de linfoma em cães. Revista Científica de Medicina Veterinária-Pequenos Animais e Animais de Estimação, 4(12), 139-146.

Moura, V. M. B. D., Sequeira, J. L., \& Bandarra, E. P. (1999). Linfoma canino. Revista de Educação 
Continuada Em Medicina Veterinária e Zootecnia Do CRMV-SP, 2(2), 29-33. DOI: https://doi.org/10.36440/recmvz.v2i2.3383

Ribeiro, R. C. S., Aleixo, G. A. S., \& Andrade, L. S. S. (2017). Linfoma canino: revisão de literatura. Medicina Veterinária, 9(1-4), 10-19.

Silva, M. C. L., \& Sequeira, J. L. (2016). Linfoma canino: Revisão de literatura com ênfase no linfoma difuso de grandes células B. Veterinária e Zootecnia, 23(4), 561-576.

Souza, T. M., Fighera, R. A., Irigoyen, L. F., \& Barros, C. S. L. (2006). Estudo retrospectivo de 761 tumores cutâneos em cães. Ciência Rural, 36(2), 555-560. DOI: https://doi.org/10.1590/s0103$\underline{84782006000200030}$

Recebido: 9 de maio, 2020.

Aprovado: 8 de junho, 2020.

Disponível online: 16 de agosto, 2020.

Licenciamento: Este artigo é publicado na modalidade Acesso Aberto sob a licença Creative Commons Atribuição 4.0 (CC-BY 4.0), a qual permite uso irrestrito, distribuição, reprodução em qualquer meio, desde que o autor e a fonte sejam devidamente creditados. 